\title{
Retroviral-mediated transfer of genes encoding interleukin-2 and interleukin-12 into fibroblasts increases host antitumor responsiveness
}

\author{
Anne-Sophie Govaerts, Thierry Guillaume, Marc André, Babak Bayat, Anne-Marie Feyens, \\ Teresa S. Hawley, A. Z. C. Fong, Robert G. Hawley, and Michel Symann \\ Laboratory of Experimental Oncology and Hematology, Catholic University of Louvain, Brussels, Belgium, \\ and Oncology Research Laboratories, The Toronto Hospital Research Institute, Toronto, Ontario, Canada.
}

\begin{abstract}
The transfer of genes encoding cytokines into tumor cells has emerged as a new strategy to increase in vivo host reactivity to a variety of tumors. Because gene transfer into tumor cells cannot be easily applied in the clinical setting, we have developed an experimental model of gene transfer into fibroblasts and examined the capacity of these engineered cells to elicit an antitumor immune response. Interleukin-12 (IL-12) is a heterodimeric cytokine with pleiotropic activities presenting strong antitumor and antimetastatic effects in murine models. A bicistronic retroviral vector was constructed that contained the cDNAs encoding both chains ( $\mathrm{p} 40$ and $\mathrm{p} 35$ ) of murine IL-12 separated by an internal ribosomal entry site sequence. Syngeneic cutaneous fibroblasts obtained from newborn mice and transduced to secrete either IL-12 or IL-2 were injected subcutaneously with B16F0 or B16F1 melanoma cells. The time of tumor occurrence and overall survival of mice were significantly prolonged when B16F1 cells were coinjected with cytokine-producing fibroblasts compared with B16F1 alone or B16F1 together with unmanipulated fibroblasts. Systemic effects were seen in the mice injected with either IL-2- or IL-12-secreting fibroblasts, with the highest proliferation capability and interferon- $\gamma$ production observed in vitro from splenocytes from recipients of IL-2-secreting fibroblasts. Injection of IL-2-secreting fibroblasts or coinjection of IL-2- and IL-12-producing fibroblasts resulted in a significant increase of survival in the B16F0 model; in some cases, complete disease eradication was observed. These results suggest that cutaneous fibroblasts represent a target of choice for gene transfer and would be useful in the treatment of minimal residual disease in humans.
\end{abstract}

Key words: Tumor immunotherapy; interleukin-12; interleukin-2; cancer gene therapy.

$I^{\mathrm{n}}$ mmunotherapy using cytokines and/or costimulatory molecules has emerged in recent years as an innovative strategy in the treatment of cancer. ${ }^{1}$ The antitumor activity of a number of cytokines has been demonstrated in various animal tumor models. ${ }^{2-5}$ Interleukin-12 (IL12) has attracted much enthusiasm in devising immunotherapeutic strategies. IL-12, a heterodimeric cytokine composed of two disulfide-linked subunits of $\sim 40$ and 35 $\mathrm{kDa}$ is naturally produced by activated antigen ( $\mathrm{Ag}$ )presenting cells. $^{6-9}$ IL-12 functions as a growth factor of $\mathrm{T}$ and natural killer (NK) cells, promotes the development of cell-mediated immunity (T-helper type 1 cells),,${ }^{9,10}$ induces the secretion of interferon- $\gamma$ (IFN- $\gamma$ ) from resting and activated $\mathrm{T}$ and NK cells, and increases the cytotoxic activity of NK/lymphokine-activated killer

Received June 1, 1998; accepted November 1, 1998.

Address correspondence and reprint requests to Dr. Anne-Sophie Govaerts, Laboratory of Experimental Oncology and Hematology, Catholic University of Louvain, 54 Avenue Hippocrate, UCL54.71, 1200 Brussels, Belgium.

(C) 1999 Stockton Press 0929-1903/99/\$12.00/+0 cells and the specific cytotoxic T-lymphocyte (CTL) response. $^{11-15}$ In addition, IL-12 has been shown to present antiangiogenic properties. ${ }^{16}$ IL-12 has been demonstrated to have important antitumor and antimetastatic effects against a number of murine tumors following administration by several routes. ${ }^{17-25}$ Endogenous IL-12 appears necessary for tumor rejection, supporting its role in cancer immunotherapy. ${ }^{26,27}$ In vitro data suggest that a combination of IL-2 and IL-12 may result in additive or synergistic immunomodulatory effects, displaying a higher in vivo antitumor efficacy than that obtained with either cytokine alone. ${ }^{20,22}$ IL-2 can also enhance the expression of IL-12 receptors on $\mathrm{T}$ and NK cells. ${ }^{28}$

The present study was designed to examine and compare the antitumor immunity induced by the administration of IL-2- or IL-12-transduced fibroblasts in two melanoma murine models, B16F0 and B16F1. The possible additive effect of the coexpression of IL-2 and IL-12 at the tumor site was also tested by the conjunctional use of IL-2- and IL-12-transduced fibroblasts. Furthermore, we explored the capacity of the host to mount a cell response to the cytokine produced. A 
bicistronic retroviral vector producing both genes p35 and p40 of IL-12 was constructed for this study.

\section{MATERIALS AND METHODS}

\section{Construction of murine stem cell virus retroviral vector (MSCV)-IL-12 and -IL-2 retroviral vectors}

The cDNA for the p40 and p35 subunits of murine IL-12 (mIL-12) was cloned into the MSCV. This vector contains a neo gene under the control of a phosphoglycerate kinase promoter. ${ }^{29,30}$ Polymerase chain reaction (PCR) amplification of the p40 subunit cDNA cloned in pBS vector (provided by M. K. Gately, Hoffmann-La Roche, Nutley, NJ) was performed in a $50-\mu \mathrm{L}$ volume containing $15 \mathrm{pmol}$ of each primer, $80 \mu \mathrm{M}$ of deoxynucleoside triphosphate, $1 \mathrm{mM} \mathrm{MgCl}$, and $1.25 \mathrm{U}$ Goldstar Taq polymerase (Eurogentec, Liège, Belgium) on an MJ Research thermocycler (Waltham, Mass). The primers used for p40 were 5'-GAACAAAAGTTAACGGGCTGCAGGTCGATC-3' (sense) and 5'-TAGGGCCTCGAGCTAGGATCGGACC-3' (antisense) and included restriction site sequences for $\mathrm{HpaI}$ and $\mathrm{XhoI}$ (underlined) in the sequence of the sense and antisense primers, respectively. PCR was performed for 30 cycles. Each cycle consisted of $94^{\circ} \mathrm{C}$ for 40 seconds, $65^{\circ} \mathrm{C}$ for 1 minute, and $72^{\circ} \mathrm{C}$ for 1.5 minutes. Similarly, p35 cDNA (provided by Hoffmann-La Roche) was amplified from cDNA cloned in a pBS vector using the following primers: 5'-AACAAAAGATCTGGCTGCAGGTCGATCG-3' (sense) and 5'-AGCTAAGATCTCTAATGAATTCTCA-3' (antisense) that contained BglII sites for cloning into MSCV (annealing temperature of $60^{\circ} \mathrm{C}$ ). The expected lengths of resulting the p40 PCR and p35 products were 1053 base pairs and 649 base pairs, respectively. Amplified p40 and p35 products were ligated into the HpaI and XhoI and BglII sites of MSCV, respectively.

Between the two cDNAs, an intervening encephalomyocarditis virus (EMCV) internal ribosomal entry site (IRES) sequence obtained by PCR amplification of the PCITE plasmid (sense: $5^{\prime}$-ATAGGGAGACTCGAGTTCCGCCCC-3' and antisense 5'-GTTCCATGGCTCGAGCCATATTAT-3') of the pCITE plasmid (Novagen, Abingdon, UK) was subcloned into the XhoI site at the $3^{\prime}$ terminus of the p40 cDNA. The IRES sequence allowed for the coordinated expression of the two subunits as a bicistronic transcript in a cap-independent manner. ${ }^{26,27}$ Retrovirus vector constructs were transfected into the GP+E86 murine ecotropic packaging cell line generously provided by A. Bank ${ }^{31}$ (Columbia University, New York, NY) by standard calcium phosphate coprecipitation. The supernatant of the G418-resistant cells was used to infect the amphotropic PA317 packaging cell line provided by R. C. Mulligan (Howard Hughes Medical Institute, Harvard Medical School, Boston, Mass). ${ }^{32}$ Under G418 selection $(500 \mu \mathrm{g} / \mathrm{mL})$, several clones were isolated; the reverse transcriptase activity contained within the virus particles was measured to check for the presence of retrovirus in the conditioned media. The clones with the highest activity were titrated by supernatant infection of NIH3T3 cells. As the highest titer was only $6 \times 10^{2}$ colony-forming units (CFU)/mL, the supernatant of this clone was used to infect the GP+E86 cells. The absence of replication-competent virus in conditional medium was confirmed by a test measuring the reverse transcriptase activity contained in the viral particles by $\left[{ }^{3} \mathrm{H}\right]$ thymidine incorporation of trichloroacetic acid-precipitable material. The MSCV-mIL-2 vector was constructed by inserting a 0.6-kilobase PstI-DraI fragment of mIL-2 cDNA (pmut-1; no. 37553, American Type Culture
Collection (ATCC), Manassas, Va) to which 5' BamHI and 3' XhoI sites had been added (by subcloning into PstI/EcoRVdigested pBluescript $\mathrm{SK}^{-}$) between the $B g l \mathrm{II}$ and $\mathrm{XhoI}$ sites of the polylinker in MSCV v2.2. The MSCV-mIL-2 plasmid was linearized by digestion with NdeI and was electroporated into $\mathrm{GP}+\mathrm{E} 86$ cells.

\section{Quantification of IL-12, IL-2, and IFN- $\gamma$}

The proliferative response of day 4 human phytohemagglutinin (PHA)-activated lymphoblasts was used to quantify the bioactivity of the IL-12 produced in the supernatant of infected cells (GP+E86-producing cells and fibroblasts). Stimulation of $10^{4}$ lymphoblasts was performed in $100 \mu \mathrm{L}$ of medium in roundbottom, 96-well microtiter plates (Falcon, Becton Dickinson, Franklin Lakes, NJ) using serial dilutions of supernatant with or without anti-murine p40 antibody (Ab) C17.4 added in excess and was measured as described previously. ${ }^{33}$ After 48 hours of stimulation, lymphoblasts were pulsed with $\left[{ }^{3} \mathrm{H}\right]$ thymidine (DuPont New England Nuclear, Boston, Mass) and collected on a cell harvester (Skatron, Lier, Norway) 18 hours later. The incorporation of $\left[{ }^{3} \mathrm{H}\right]$ thymidine into DNA was quantitated by liquid scintillation counting. Results expressed in $\mathrm{ng} / 10^{6}$ cells/24 hours were calculated from a standard curve using defined doses of recombinant mIL-12 (rmIL-12), kindly provided by Maurice Gately (Hoffmann-La Roche), ranging from $15.6 \mathrm{pg} / \mathrm{mL}$ to $16 \mathrm{ng} / \mathrm{mL}$. Measurements of the IL-12, IFN- $\gamma$, and IL-2 present in sera and culture supernatants were performed using enzyme-linked immunosorbent assay (ELISA) kits (Genzyme, Cambridge, Mass).

\section{Cell lines}

B16F0 and B16F1 melanomas and PA317 packaging cell lines were purchased from ATCC. GP+E86 was kindly provided by Dr. A. Bank. ${ }^{31}$ Tumor cells and GP+E86 and PA317 packaging cell lines were maintained in culture in Dulbecco's modified Eagle's medium supplemented with $10 \%$ heat-inactivated fetal calf serum, $2 \mathrm{mM}$ glutamine, $100 \mu \mathrm{g} / \mathrm{mL}$ streptomycin, and $100 \mathrm{U} / \mathrm{mL}$ penicillin (Life Technologies, Gaithersburg, Md). GP+E86 cells were selected in HXM (hypoxanthine, xanthine, mycophenolic acid) medium as described previously. ${ }^{30}$ The tumorigenic activity of B16F1 and B16F0 was assayed in mice that had been injected subcutaneously (s.c.) with 0.2 $\mathrm{mL}$ of serum-free phosphate-buffered saline (PBS) cell suspension at various concentrations to determine the minimal number of tumor cells required for tumor development. The numbers of cells injected in the present experiments were of $10^{4}$ and $5 \times 10^{4}$ cells for the B16F0 and B16F1 cell lines, respectively.

\section{Animal experiments}

C57BL/6 mice were purchased from Iffa Credo (L'Arbresle, France) and used in experiments at 6-10 weeks of age. Exponentially growing tumor cells were harvested by brief trypsination, washed, and used to inoculate groups of animals s.c. in the shaved area of the right flank. The number of mice for each group is specified in Results. The emergence of palpable tumors was examined every other day, and tumor size was determined by microcaliper measurement of perpendicular tumor diameters in millimeters. Used nontransduced or genetically modified fibroblasts were coadmixed with autologous tumor cells and injected in $0.2 \mathrm{~mL}$ of PBS at different $\mathrm{B} 16 \mathrm{~F} 0$ tumor to fibroblast (T:F) ratios (1:5 and 1:10). 


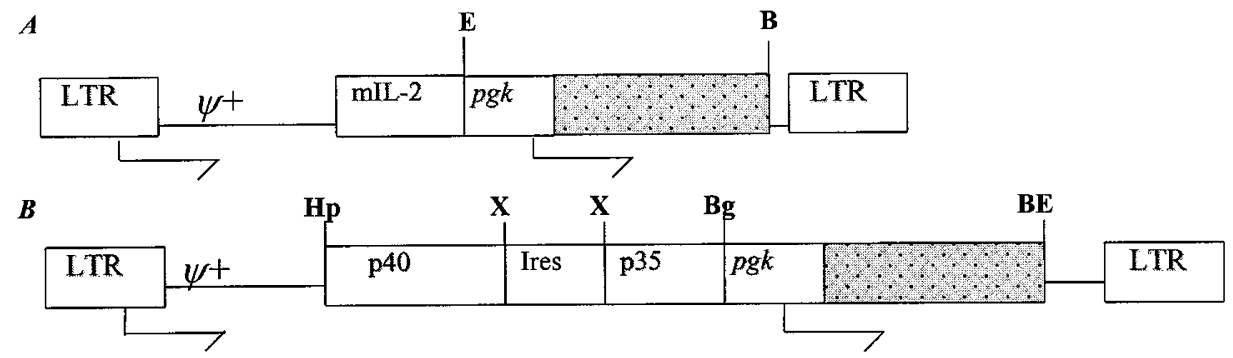

Figure 1. Schematic maps of the retroviral vector MSCV-mIL-2 (A) and the bicistronic retroviral vector MSCV (B) containing cDNA for the p35 and p40 subunits of $\mathrm{mlL}-12$ separated from EMCV by an IRES sequence. Restriction sites are indicated. E, EcoRl; Hp, Hpal; $\mathrm{Bg}, \mathrm{Bg} / \mathrm{ll} ; \mathrm{B}, \mathrm{BamHI}$ X, Xhol. The coding region for $\mathrm{Neo}^{r} \mathrm{CDNA}$ is indicated in .
Preparation and assay of syngeneic fibroblasts expressing IL-12 or IL-2

Syngeneic fibroblasts were obtained from the skin of newborn mice that had been mechanically and enzymatically digested with $0.25 \%$ collagenase (Sigma, St. Louis, Mo) and $4.8 \mathrm{U} / \mathrm{mL}$ dispase (grade II, Boehringer Mannheim, Mannheim, Germany) at $37^{\circ} \mathrm{C}$ for $1-2$ hours under rotational agitation in the presence of RPMI 1640 supplemented with $20 \%$ fetal bovine serum (unpublished observations, N. Naffak, Institut Pasteur, Paris, France). After two washes in $1 \times$ PBS, cells were cultured in RPMI 1640 medium supplemented with $10 \%$ heat-inactivated fetal calf serum. The following day, cells were infected by exposure to undiluted E86/MSCV-IL-12 or IL-2 supernatants for 2 hours a day in the presence of polybrene $(8 \mu \mathrm{g} / \mathrm{mL}$; Life Technologies) for 5 consecutive days and subsequently selected for 3 days in complete medium with G418 at a concentration of $500 \mu \mathrm{g} / \mathrm{mL}$. IL-12 and IL-2 expression were measured in the supernatants by ELISA test.

\section{Proliferation assay}

Stimulation of $10^{5}$ splenocytes was performed in $100 \mu \mathrm{L}$ of medium in round-bottom, 96-well microtiter plates (Falcon, Becton Dickinson) with concanavalin A (Con A) $(2 \mu \mathrm{g} / \mathrm{mL})$, Con A plus IL-2 (2 ng/mL), Con A plus IL-12 $(1.7 \mathrm{ng} / \mathrm{mL})$, or medium alone. Addition of $\left[{ }^{3} \mathrm{H}\right]$ thymidine and collection of samples were performed as described previously for IL-12 quantification.

\section{Immunohistological analysis}

Tumors were embedded into optimal cutting temperature compound (Miles, Elkert, Ind), snap-frozen in isopentane that had been precooled in liquid nitrogen, and stored at $-80^{\circ} \mathrm{C}$ until sectioned. Briefly, tissue sections were prepared, fixed in cold acetone, and immunostained with rat anti-mouse monoclonal Ab (mAb) against CD8 (L3T4), CD4 (Ly-2), and CD11c (Mac- $1 \alpha \mathrm{M}$ chain) cells (all purchased from PharMingen San Diego, Calif). Biotinylated mAbs were added at concentrations optimally titrated against mouse splenocytes and linked to streptavidin-peroxidase reagent. Sections were then incubated with peroxidase substrate $\left(0.03 \% \mathrm{H}_{2} \mathrm{O}_{2}\right.$ and $0.06 \% 3^{\prime}$-diaminobenzidine) and counter-stained with hematoxylin.

\section{Statistics}

The Student $t$ test was performed to interpret the significance of difference between two experimental groups (presented as mean $\pm \mathrm{SD}$ ). Kruskal-Wallis analysis was performed to compare differences in survival. Differences were considered to be statistically significant when the $P$ value was $<.05$ (Dunn's test).

\section{RESULTS}

Construction of MSCV-IL-2 and MSCV-IL-12 retroviral vectors and establishment of E86/MSCV-IL-2 and IL-12 cell lines

MSCV-IL-2 (A) and MSCV-IL-12 (B) constructs are depicted in Figure 1. The IL-2-producing cell line was obtained by the transfection of MSCV-mIL-2 plasmid in $\mathrm{GP}+\mathrm{E} 86$ cells. Vector-containing supernatant was collected 24 hours later and used to transduce tunicamycintreated $(0.1 \mathrm{mg} / \mathrm{mL}$ for 16 hours $) \mathrm{GP}+\mathrm{E} 86$ cells. Pooled populations of stable GP+E86 transductants (E86/ MSCV-mIL-2 cells) produced recombinant MSCVmIL-2 vector at a titer of $10^{6} \mathrm{CFU} / \mathrm{mL}$. An IL-12producing cell line was obtained after transfection into GP + E86 cells and serial infection of PA317 and GP + E86 cells. Different clones were selected for their production of IL-12 using a human lymphoblast proliferation assay. The specificity of the IL-12 activity was confirmed using an $\mathrm{Ab}$ (C17.8) directed against $\mathrm{p} 40$ preventing the binding of IL-12 to its receptor (Fig 2).
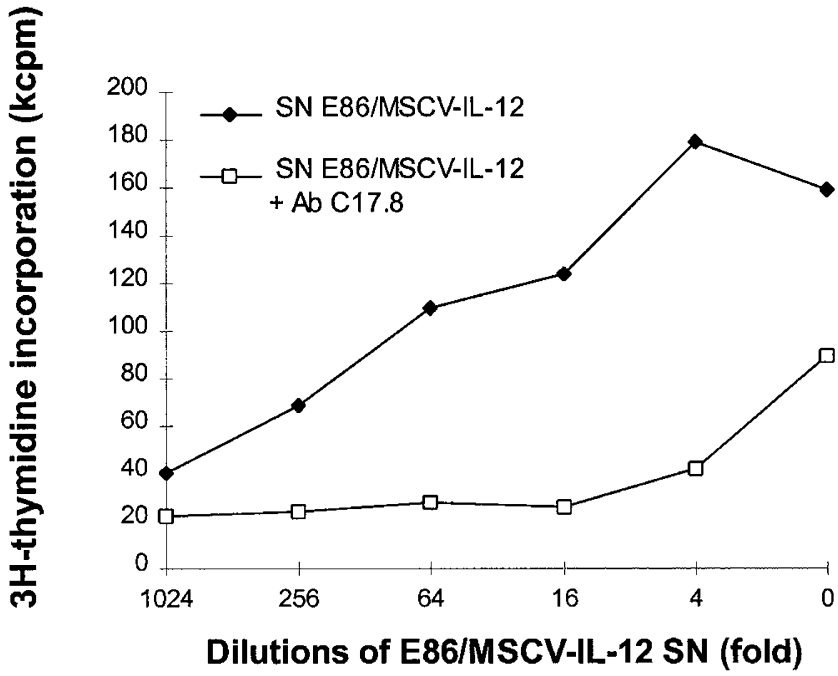

Figure 2. Quantification of $\mathrm{mlL}-12$ in the supernatant produced by the E86/MSCV-IL-12 clone by proliferation assay. A total of 10,000 day 4 PHA-activated lymphoblasts were cultured for 48 hours with diluted supernatant in the absence $(\checkmark)$ or in the presence $(\square)$ of $\mathrm{IL}-12-$ neutralizing $\mathrm{Ab} \mathrm{C}$ 17.4. Proliferation in response to IL-12containing medium was measured by $\left[{ }^{3} \mathrm{H}\right]$ thymidine incorporation. 
Table 1. IL-12 and IL-2 Secretion from Transduced and Untransduced Packaging Cell Lines and Vector-Transduced Fibroblasts (Mean \pm SD)

\begin{tabular}{lll}
\hline \multicolumn{1}{c}{ Cells } & \multicolumn{1}{c}{ IL-12 production } & \multicolumn{1}{c}{ IL-2 production } \\
\hline GP+E86 & ND & ND \\
E86/MSCV-IL-12 & $212 \pm 67(164-260)$ & NT \\
E86/MSCV-IL-2 & NT & $9 \pm 3.3(6.7-11.4)$ \\
Transduced fibroblasts & $200(52-483)$ & $0.4 \pm 0.32(0.1-1.12)$ \\
\hline
\end{tabular}

Results are expressed in $\mathrm{ng} / 10^{6}$ cells/24 hour (range) as determined by ELISA (three to seven measurements performed); ND, nondetectable; NT, not tested.

One clone with a titer of $5 \times 10^{3} \mathrm{CFU} / \mathrm{mL}$-producing $260 \mathrm{ng}$ IL-12/10 $0^{6}$ cells after 24 hours was isolated and termed E86/MSCV-IL-12. Supernatant of E86/MSCVIL-12 was used to infect fibroblasts.

\section{Generation of fibroblasts expressing IL-2 and IL-12}

Virus-containing cell-free supernatants of E86/MSCVIL-2 and E86/MSCV-IL-12 were used to infect autologous fibroblasts cells 2 hours a day for 5 consecutive days with renewal in infected cells of medium each day. Cells were subsequently selected for 3 days in G418. The presence of the provirus in infected cells was demonstrated by Southern blot analysis. IL-2 secretion was measured by ELISA performed on different supernatants. Production of the IL-12 by fibroblasts was measured in the supernatant using the proliferation assay after serial dilution and by ELISA. Both tests gave comparable values (Table 1).

\section{Growth of B16F0 tumor cells}

We explored the use of the immunomodulants IL-2 and IL-12 alone or in combination to control melanoma tumor growth. To analyze the effect of IL-2 or IL-12 on tumor growth, C57BL/6 mice were administered s.c. $10^{4}$ B16F0 melanoma cells alone or mixed with 5 or $10 \times 10^{4}$ fibroblasts corresponding to two different $\mathrm{T}: \mathrm{F}$ ratios (1:5 and 1:10) of either untransduced, IL-12-, or IL-2-transduced fibroblasts. The appearance and size of the tumors were monitored every 2 days. Time of tumor appearance was defined as the time of detection of palpable tumor $(2 \mathrm{~mm})$. A delay in tumor appearance and an increase in survival time could only be observed when IL-2-producing cells were coinjected with tumor cells at the 1:10 T:F ratio, whereas IL-12-secreting fibroblasts did not have consistent antitumor activity (Table 2a). The effect of IL-2 was directly dependent upon the number of fibroblasts injected, because no effects were observed for the 1:5 T:F ratio. Indeed, the tumor growth rate for the group of mice injected with the highest number of IL-2 fibroblasts (T:F ratio $=1: 10)$ was significantly reduced compared with that seen for mice treated with IL-2 at lower dose $(\mathrm{T}: \mathrm{F}$ ratio $=1: 5)$ or with $\mathrm{B} 16 \mathrm{~F} 0$ alone or $\mathrm{B} 16 \mathrm{~F} 0$ and untransduced fibroblasts $(P<.05$; Student's $t$ test $)$. The combined injection of IL-2- and IL-12-producing cells at a 1:5:5 T:F:F ratio also delayed the appearance of tumors and reduced the tumor development rate (Table 2a). However, this coadministration was not superior to the injection of IL-2-secreting cells alone at the 1:10 T:F ratio. Injection of IL-2-expressing fibroblasts $(\mathrm{T}: \mathrm{F}$ ratio $=1: 10)$ or coinjection of IL-2- and IL-12-producing fibroblasts (T:F ratio $=1: 5: 5)$ has an effective antitumor effect, because a rejection of tumor cells was observed in 3 of 12 (25\%) and 3 of $14(21 \%)$ mice, respectively. Fibroblasts secreting IL-2 $(\mathrm{T}: \mathrm{F}$ ratio $=1: 10)$ and fibroblasts secreting both IL-2 and IL-12 (T:F ratio = 1:5:5) prolonged median survival by 21.5 and 18.5 days, respectively $(P<.05$; Kruskal-Wallis (Dunn's test); Figure 3).

\section{B16F1 model}

Similar to the B16F0 model, $5 \times 10^{4} \mathrm{~B} 16 \mathrm{~F} 1$ tumor cells were injected alone or in combination with $5 \times 10^{5}$ fibroblasts (untransduced fibroblasts, fibroblasts transduced by MSCV-IL-2 or MSCV-IL-12, or a mixture of

Table 2. Number of Days \pm SD for Tumor Appearance and Death of Mice Injected with B16F0 (a) or B16F1 (b) Tumor Cells

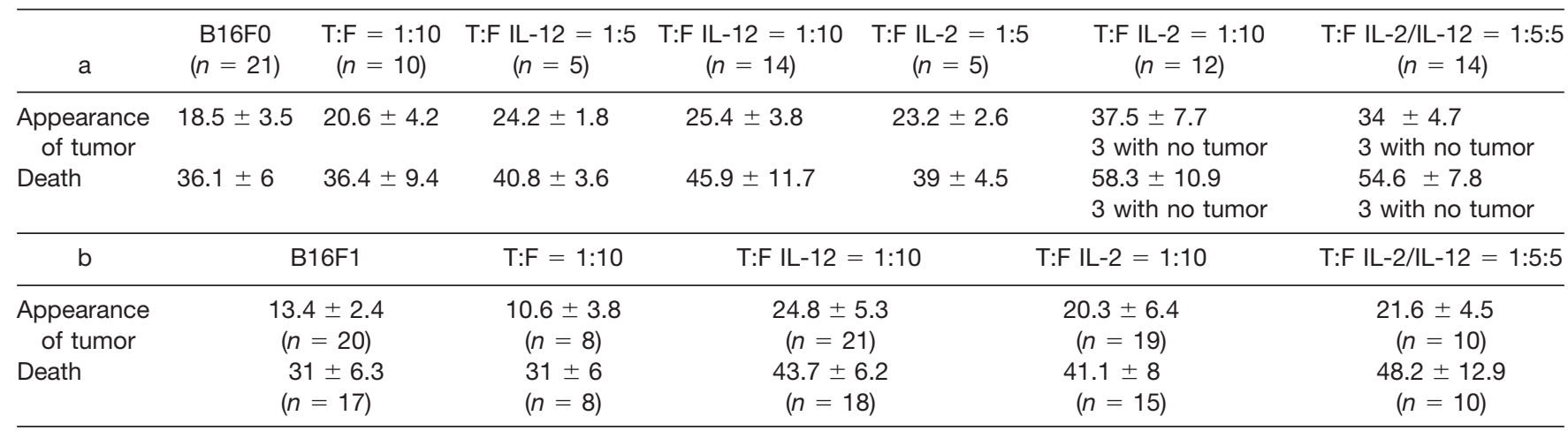

Cells were administered to mice concomitantly with IL-2- and IL-12-transduced or nontransduced fibroblasts. Ratios of tumor cells (T) on transduced (FIL-12 or FIL-2) or nontransduced (F) fibroblasts are indicated. For groups of more than five mice, the data shown are the results of pools of two or three experiments. $n=\mathrm{nb}$ of mouse.

a) Statistical significance for the death rate $(P<.05)$ was observed between a T:F IL-2 ratio of $1: 10$ and T:F IL-2/IL-12 ratio of $1: 5: 5$ compared with B16F0 alone or B16F0 and fibroblasts untransduced or transduced with T:F = IL-2 (T:F 1:10, T:F IL-2 = 1:5).

b) $P<.05$ between controls groups (B16F1 alone and a T:F ratio of 1:10) and groups of mice injected with cytokine-producing cells. 


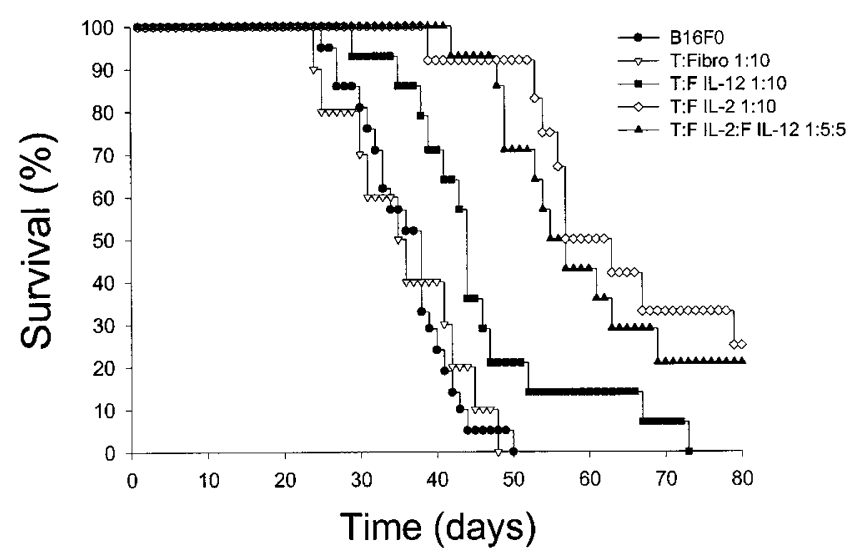

Figure 3. Survival curve of mice injected with $10^{4} \mathrm{~B} 16 \mathrm{~F} 0$ alone or coinjected with transduced fibroblasts. $P<.05$ for B16F0 versus B16F0-Fib-IL-2 or IL-2/IL-12 by Kruskal-Wallis analysis (Dunn's test); $\mathrm{T}: \mathrm{F}$ ratio $=1: 10$. $\mathrm{B} 16 \mathrm{~F} 0$ versus $\mathrm{B} 16 \mathrm{~F} 1-\mathrm{Fib}$ or $\mathrm{B} 16 \mathrm{~F} 0-\mathrm{Fib}-\mathrm{IL}-12$ : not significant.

IL-2- and IL-12-producing fibroblasts). The T:F ratio $(1: 10)$ was the same as the ratio that gave optimal results in the previous experiments with B16F0. Effects of cytokine-engineered cells were evaluated by time of tumor appearance, growth rate, phenotype and cytokine production of splenocytes, and histological features at the tumor site.

Injections of $\mathrm{B} 16 \mathrm{~F} 1$ cells with cytokines producing fibroblasts delayed significantly the time of tumor occurrence in comparison with injections of B16F1 cells alone or mixed with unmanipulated fibroblasts (Table $2 b$ ). By day 17 , all control mice injected with tumor cells alone developed a tumor that grew progressively. Mice inoculated with untransduced fibroblasts showed tumor growth that was similar to that observed in mice injected with tumor cells alone. At 19 days postinjection, the mean tumor size for control mice was $69.5 \pm 56.8 \mathrm{~mm}^{2}$ $(n=14)$, whereas no tumor mass was detectable at this time in mice treated with fibroblasts genetically engineered to produce IL-12. The tumor growth rate for the groups of mice receiving IL-2- $(\mathrm{T}: \mathrm{F}$ ratio $=1: 10)$, IL-12$(\mathrm{T}: \mathrm{F}$ ratio $=1: 10)$, or IL-2- and IL-12- $(\mathrm{T}: \mathrm{F}$ ratio $=$ 1:5:5) transduced fibroblasts was significantly reduced compared with mice receiving $\mathrm{B} 16 \mathrm{~F} 1$ alone or $\mathrm{B} 16 \mathrm{~F} 1$ and untransduced fibroblasts $(P<.05)$. No palpable tumor was observed in mice receiving IL-12-, IL-2-, or IL-2/IL-12-transduced fibroblasts before days 20, 13, and 15 respectively. For those groups, mean tumor sizes were $129( \pm 70) \mathrm{mm}^{2}, 168( \pm 130) \mathrm{mm}^{2}$, and $122( \pm 48) \mathrm{mm}^{2}$ by day 33; more than half of the mice injected with tumor cells alone were dead at that time (Student's $t$ test; Fig 4).

IL-2- or IL-12-secreting fibroblasts at a 1:10 ratio or IL-2 and IL-12 at a T:F:F ratio of 1:5:5 prolonged median survival (in comparison with unmodified fibroblasts) by $9,10.5$, and 16 days, respectively (Fig 5). These differences were statistically significant (Kruskal-Wallis (Dunn's test); $P<.05$ ). No statistically significant differences in time of tumor appearance were observed
A

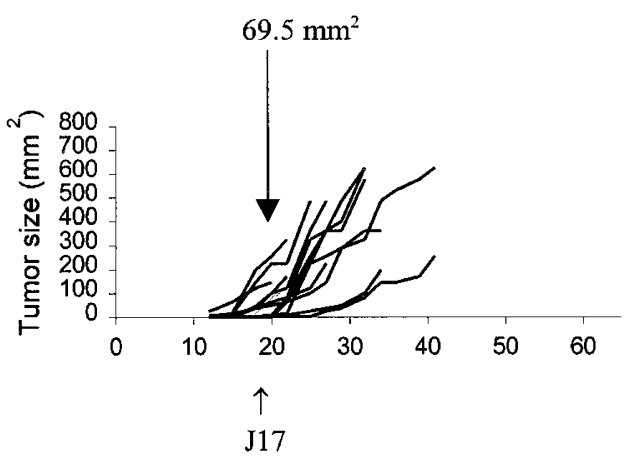

B

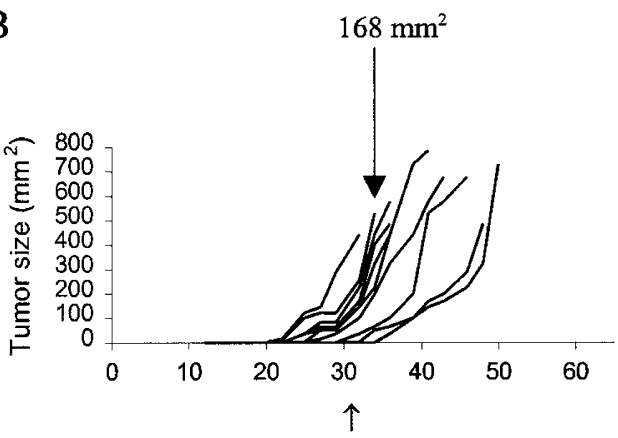

$\mathrm{J} 31$

$\mathrm{C}$

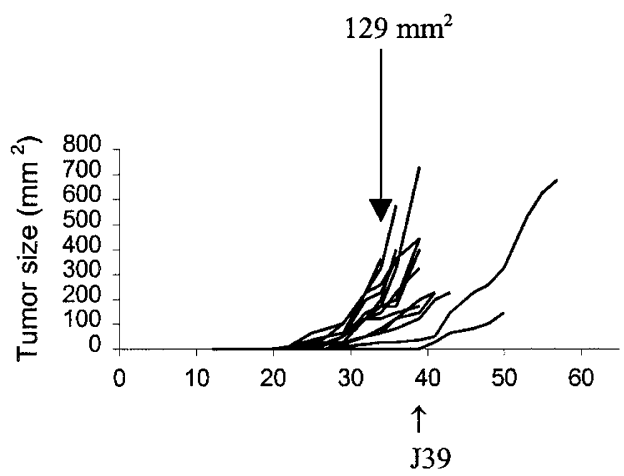

D

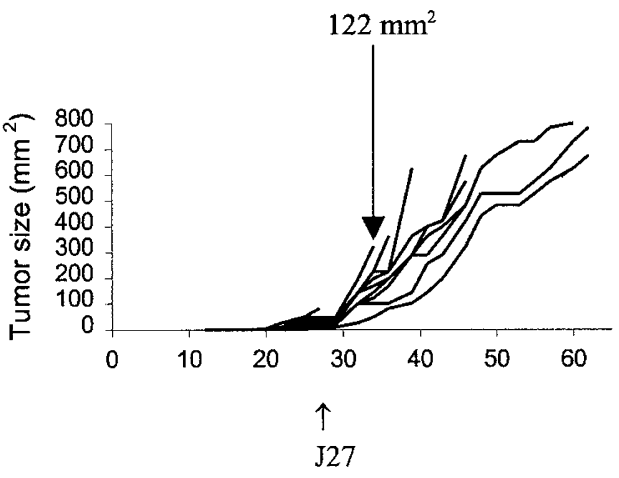

Days post-injection

Figure 4. B16F1 tumor growth $\left(\mathrm{mm}^{2}\right)$ according to time postinoculation. Each line corresponds to an individual mouse. Tumor growth in mice injected with tumor cells alone (A), coinjected with IL-2producing fibroblasts (T:F ratio $=1: 10)(B)$; coinjected with IL12-producing fibroblasts $(T: F$ ratio $=1: 10)(C)$; or coinjected with IL-2- and IL-12-producing fibroblasts (T:F ratio $=1: 5: 5)$ (D). Tumor appearance in all mice per group is indicated by $\uparrow$; mean tumor size is shown at day 19 for group A and at day 33 for all other groups. 


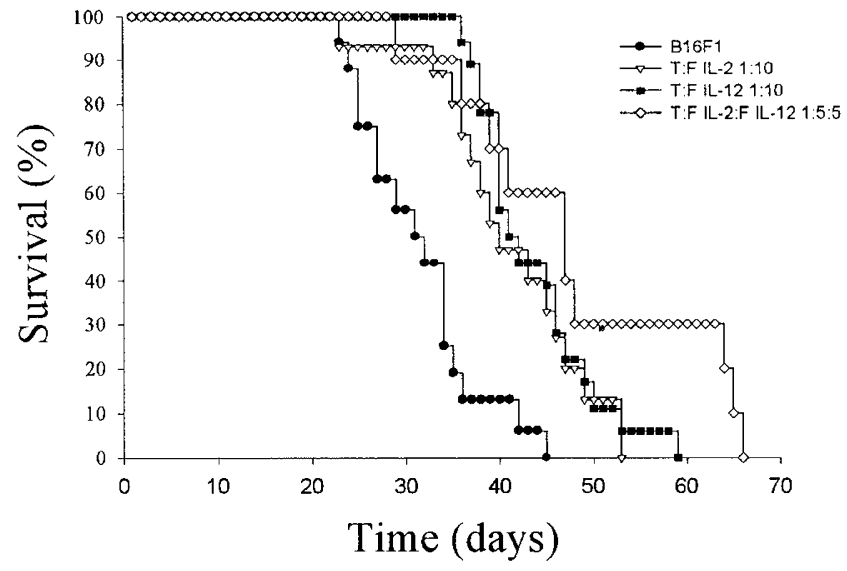

Figure 5. Survival curve of mice injected with $5 \times 10^{4}$ B16F1. $P<$ .05 for B16F1 versus B16F1-Fib-IL-12, IL-2, or IL-2/IL-12 by Kruskal-Wallis analysis (Dunn's test). $X=20,21,19$, or 10 mice analyzed from the groups injected with tumor cells alone, injected with tumor cells and IL-12- or IL-2-transduced fibroblasts, or coinjected with IL-2- and IL-12-producing fibroblasts, respectively.

between groups of mice injected with genetically modified fibroblasts (IL-2 versus IL-12 versus IL-2 plus IL-12; Figs 4 and 5).

\section{Effects on cell functions}

Three mice of groups injected with B16F1 cells alone $\left(5 \times 10^{4}\right)$ or B16F1 cells coinjected with IL-2- or IL-12-secreting fibroblasts ( $\mathrm{T}: \mathrm{F}$ ratio $=1: 5: 5)$ were sacrificed at 15 days postinoculation. Cellular counts were similar in each group. The proportions of splenocytes marked with CD3, CD8, CD4, and CD22 Abs were not statistically different in the various groups according to fluorescence-activated cell sorter analyses (data not shown). Splenocytes from mice injected with B16F1 cells alone or with B16F1 cells plus IL-12- or IL-2-transduced fibroblasts were collected and tested by proliferation assay and for IFN- $\gamma$, IL-2, and IL-12 production following in vitro culture in the presence or absence of Con

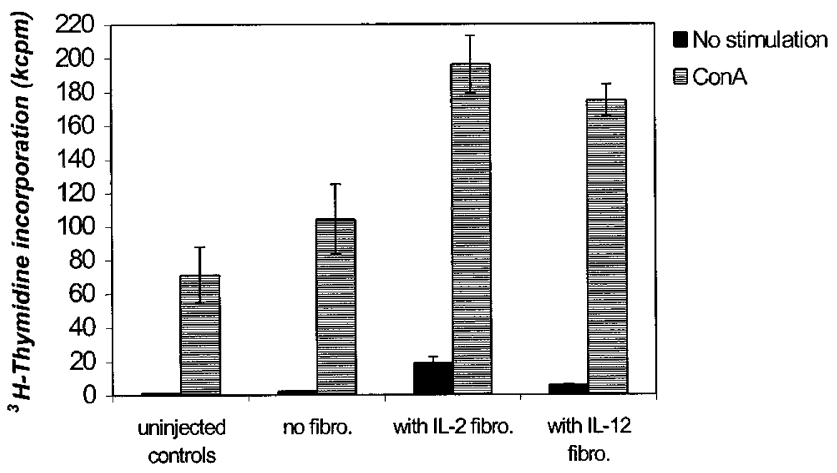

Figure 6. Proliferation of splenocytes $(n=3)$ was determined on day 15 after inoculation of mice receiving B16F1 \pm fibro-IL-2 or fibro$\mathrm{IL}-12$. According to the Student t3 test, $P=.015$ for B16F1 Con A-stimulated splenocytes versus B16F1-Fib-IL-2 or IL-12 and $P=$ .033 for B16F1-Fib-IL-2 versus B16F1-Fib-IL-12.

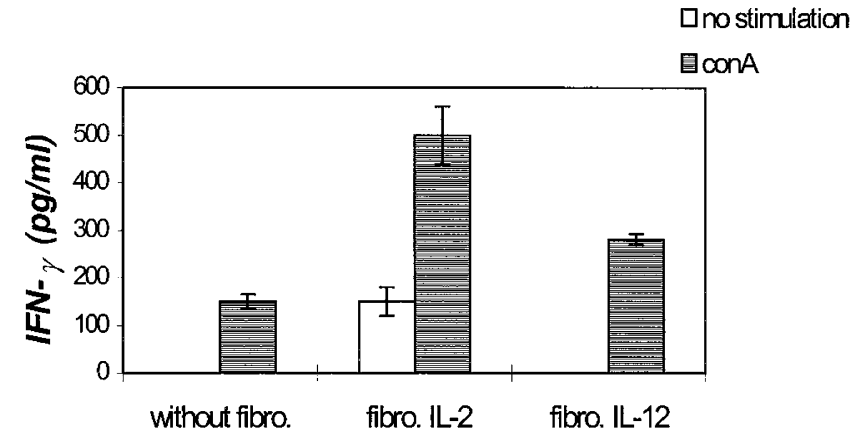

Figure 7. Induction of IFN- $\gamma$ by inoculation of fibroblasts in vivo. IFN- $\gamma$ was measured by ELISA in a supernatant of splenocytes stimulated or not with Con $A$ from mice injected 1 month previously with B16F1 alone or B16F1 admixed with FIL-2 or FIL-12. Supernatant was collected after a 48-hour incubation.

$\mathrm{A} \pm$ rmIL-2 or Con $\mathrm{A} \pm$ rmIL-12; $n=3$ for each group. The results of the proliferation assays in the presence and absence of Con A are given in Figure 6. No statistical difference was seen for the stimulation situations. The IL-12 secretion detected by ELISA in the sera was similar in the diverse groups $(0.1 \mathrm{ng} / \mathrm{mL})$. Only one mouse from the IL-12 group showed a low serum level of IFN- $\gamma(40 \mathrm{pg} / \mathrm{mL})$. The detection of IFN- $\gamma$ by ELISA in splenocyte cell cultures in the presence or absence of Con A is shown in Figure 7. Without Con A stimulation, IFN- $\gamma$ secretion was detected in mice injected with tumor cells and IL-2-producing fibroblasts. Following stimulation with Con A, a statistically significant increase of IFN- $\gamma$ was observed in mice receiving IL-2producing fibroblasts (Student $t$ test; $P=.039$ ). No serum IL-2 was detected. A trace of IL-2 production was found in unstimulated splenocyte cell cultures $(43 \pm 12$ $\mathrm{pg} / \mathrm{mL}$ for groups 1 and 3; $131 \pm 26 \mathrm{pg} / \mathrm{mL}$ for group 2).

Three mice from each group were sacrificed at 30 days postinoculation. By immunohistochemical staining with $\mathrm{mAb} C D 4, \mathrm{CD} 8$, and CD11c, histological slides of tumors showed an abundant infiltration of macrophages in all cases, with few $\mathrm{CD} 8^{+}$and without any $\mathrm{CD} 4^{+}$; no specific CTL response was observed in the spleens of injected mice in both tumor models (data not shown).

\section{DISCUSSION}

In the past few years, immunotherapy or gene therapy using cytokines has emerged as a new complementary approach to enhance host antitumor mechanisms of defense. ${ }^{1}$ Several studies have demonstrated that administrations of exogenous cytokines in the area of growing tumors can induce a tumor-specific immune reaction involving various types of effector cells. Regional administration has been examined using peritumoral injections of cytokines, transduced tumor cells, and, more recently, modified fibroblasts. ${ }^{3-5,27,34-37}$ However, few comparative studies of cytokines alone or combined with costimulatory molecules have been conducted. Local de- 
livery of a low amount of cytokines directly to tumor cells also has the advantage of reducing the systemic toxicity associated with exogenous administration.

In this field, studies of various immunogenic and nonimmunogenic tumors in mice involving IL-12-engineered cells have shown that those cells were capable of augmenting T-cell-mediated tumor immunity, promoting the regression of well-established primary tumors, inhibiting the formation of metastases, and inducing a protective and long-lasting response when mice were rechallenged with unmodified parental tumor cells. ${ }^{17,21,24-25}$ A s.c. injection of allogenic or syngeneic fibroblast cell lines modified to produce IL-12 can prevent the development of tumors or treat effectively established tumors. ${ }^{35,37}$ In those models, rejection of a tumor requires several injections of IL-12-producing cells. IL-2 displays similar activities to those of IL-12, but its use is limited in the clinic because of its high toxicity. ${ }^{38-40}$ IL-12 and IL-2 have demonstrated synergistic activities in vitro, namely through IFN- $\gamma$ production.

In the present study, we explored the antitumor efficiency of fibroblasts secreting cytokines at the tumor site. The difficulty in culturing, expanding, and infecting fresh human tumors limits their use as cellular vectors in the clinical setting. In addition, following in vitro culture of tumor cells, some tumor variants that may not represent the overall heterogeneity of the tumor might be expanded. Autologous cutaneous fibroblasts are readily accessible target cells that can be easily obtained from skin biopsies and outgrown in large-scale cultures. Their use in the clinic seems easily feasible and constitutes an attractive alternative method for gene therapy. Moreover, this route of administration of cytokines might be safer than systemic administration. ${ }^{41-43}$

Because coexpression of the two subunits of mIL-12 is required to obtain an immunologically functional protein ${ }^{44}$ we have constructed a bicistronic MSCV-based retroviral vector ${ }^{29}$ by inserting an IRES sequence from EMCV into a transcription unit to obtain the production of active IL-12. ${ }^{45,46}$ In mice, an excess of homodimeric p40 can inhibit heterodimeric IL-12. ${ }^{47}$ In our construct, although p40 was subcloned upstream to p35 and could have been translated in excess, we did not observe this phenomenon. Using a PHA blast bioassay, the E86/ MSCV-IL-12 cell line and infected autologous fibroblasts produced moderate to high levels of bioactive mIL-12.

Using our retroviral construct and a MSCV-based IL-2 vector, we have examined the antitumor effects of cytokine paracrine production by transduced syngeneic murine skin fibroblasts on $\mathrm{B} 16 \mathrm{~F} 0$ and $\mathrm{B} 16 \mathrm{~F} 1$ melanoma tumor models. The antitumor efficacy of either IL-12 or IL-2 alone was compared with that obtained with IL-2 and IL-12 in combination.

Injection of fibroblasts had no effect on tumor growth. This indicates that fibroblasts by themselves do not induce an immune response that might have antitumor effects. However, IL-12 or IL-2-producing fibroblasts or the coinjection of IL-2 and IL-12-secreting fibroblasts delays development of the B16F1 tumor, even if no advantage was observed with coinjection in comparison with the use of either cytokine alone.

Production of cytokines and, in particular, IL-12 at the tumor site failed to induce a complete tumor rejection, even when relatively large amounts of IL- 12 were produced by engineered fibroblasts $\left(\leq 260 \mathrm{ng} / 10^{6}\right.$ cells/24 hours), suggesting that the levels of those cytokines may be insufficient to maintain proper lymphocyte function for a long period. This may reflect the previous observation that IL-12 is more effective on established tumors rather than incipient tumors. ${ }^{22}$ In addition, time schedules of IL-12 administration may have some importance in achieving antitumor activity. Martinotti et al have shown that the systemic effect of rIL-12 was linked to the time of treatment, because B16 tumors partially regressed in response to IL-12 but resumed growth after interruption of cytokine treatment. ${ }^{48}$

As observed in the B16F1 model, there was no difference between the combination of IL-2 and IL-12 and IL-2 (T:F ratio = 1:5:5) alone in mice bearing B16F0 melanoma. B16F0 tumor establishment was delayed in those mice receiving IL-2-transduced fibroblasts $(\mathrm{T}: \mathrm{F}$ ratio $=1: 10$ ) or a mixture of IL-2- and IL-12transduced fibroblasts compared with tumor cells alone with or without untransduced fibroblasts. In the groups receiving transduced fibroblasts, a few mice did not develop any tumors.

An additive effect between IL-2 and IL-12 (ratio $\mathrm{T}: \mathrm{F}=1: 5: 5)$ was observed with numbers of fibroblasts that did not induce any effect for either cytokine alone $(\mathrm{T}: \mathrm{F}=1: 5) . \mathrm{IL}-12$ at a low dose may potentiate the IL-2 activation of $\mathrm{CD} 8^{+} \mathrm{T}$ cells by acting in particular on the $\mathrm{T}$ helper type 1 subset of $\mathrm{CD}^{+} \mathrm{T}$ cells using their helper stimulating function of cytotoxic cells responding to $\mathrm{B} 16 \mathrm{~F} 0$ or, alternatively, may amplify the activation of NK function or reduce the suppressive effect of IL-2.

As for IL-12 and IL-2 used alone, depletion studies using Abs directed against CD4, CD8, NK, macrophage $\mathrm{T}$ cells, and IFN- $\gamma$ depletion are needed to reveal the potential role of these subsets in the observed effects. Indeed, the determination of how long fibroblasts are able to produce cytokines must be of primordial importance in those experiments. Variations in the expression of costimulatory molecules and tumor Ags may certainly play a role and may partially explain why IL-12 has less of an effect on B16F0 tumorigenesis than that seen for B16F1. Both tumors have little or no expression of major histocompatibility complex class I molecules and low levels of B7. This may explain why we did not observe any primary immune response specific for the tumor and why experiments that examined the immunogenicity of antitumor formulation did not give us a clear explanation of the response induced. Indeed, we were unable to demonstrate a splenocyte CTL activity specific for $\mathrm{B} 16 \mathrm{~F} 1$ cells or T-cell infiltration at the tumor site in our model. This absence of CTL activity may reflect the poor immunogenicity of B16F1 cells lacking costimulatory and adhesion molecules. Cooperation between B7-1 and IL-12 has been shown to be more effective than immunization with either immunomodulator alone. $19,43,49$ 
Even if no CTL activity could be obtained, a systemic response was induced, as splenocytes from mice injected with IL-2 and IL-12 fibroblasts showed a higher proliferative response and higher IFN- $\gamma$ production compared with that observed in B16F1-bearing mice.

The mechanism of IL-12-induced antitumor immunity is possibly dependent upon the presence of both $\mathrm{T}$ cells and IFN- $\gamma .^{50}$ The latter seems to be responsible for an initial antitumor response by increasing tumor $\mathrm{Ag}$ presentation through major histocompatibility complex class I induction of expression and consequently increasing presentation to $\mathrm{CD} 8^{+} \mathrm{T}$ cells. ${ }^{51}$

In conclusion, the present study gives more evidence of the antitumor efficacy of a combination of IL-2 and IL-12. Multiple injections of a combination of IL-2- and IL-12-producing fibroblasts might be considered to obtain tumor eradication. Immunotherapy such as that described here could be useful in the context of minimal residual malignant disease left by cytotoxic chemotherapy. The use of IL-12- or IL-2-producing fibroblasts in conjunction or not with irradiated tumor cells as a source of tumor $\mathrm{Ag}$ is an attractive approach, because this setting should be applicable in clinical situations in which the tumor mass is reduced to its minimal volume.

\section{ACKNOWLEDGMENTS}

This work was supported by grants from Télévie-Fonds National de la Recherche Scientifique, Association Sportive contre le Cancer of Belgium, the Fabriques de Tabac réunies of Neuchatel, and the Medical Research Council of Canada (R.G.H.).

\section{REFERENCES}

1. Pardoll DM. Paracrine cytokine adjuvants in cancer immunotherapy. Annu Rev Immunol. 1995;13:399-415.

2. Musiani P, Modesti A, Giovarelli M, et al. Cytokines, tumour-cell death, and immunogenicity: a question of choice. Immunol Today. 1997;18:32-36.

3. Dranoff G, Jaffee E, Lazenby A, et al. Vaccination with irradiated tumor cells engineered to secrete murine granulocyte-macrophage colony-stimulating factor stimulates potent, specific, and long-lasting antitumor immunity. Proc Natl Acad Sci USA. 1993;90:3539-3543.

4. Allione A, Consalvo M, Nanni P, et al. Immunizing and curative potential of replicating and nonreplicating murine mammary adenocarcinoma cells engineered with interleukin (IL)-2, IL-4, IL-6, IL-7, IL-10, tumor necrosis factor $\alpha$, granulocyte-macrophage colony-stimulating factor, and $\gamma$-interferon gene or admixed with conventional adjuvants. Cancer Res. 1994;54:6022-6026.

5. Tepper RI, Mulé JJ. Experimental and clinical studies of cytokine gene-modified tumor cells. Hum Gene Ther. 1994;5:153-164.

6. Kobayashi M, Fitz L, Ryan M, et al. Identification and purification of natural killer cell stimulatory factor (NKSF), a cytokine with multiple biologic effects on human lymphocytes. J Exp Med. 1989;170:827-845.

7. Stern AS, Podlaski FJ, Hulmes JD, et al. Purification to homogeneity and partial characterization of cytotoxic lym- phocyte maturation factor from human B-lymphoblastoid cells. Proc Natl Acad Sci USA. 1990;87:6808-6812.

8. Wolf SF, Temple PA, Kobayashi M, et al. Cloning of cDNA for NK cell stimulatory factor, a heterodimeric cytokine with multiple biologic effects on T and NK cells. J Immunol. 1991;146:3074-3081.

9. D'Andrea A, Rengaraju M, Valiante NM, et al. Production of natural killer cell stimulatory factor (NKSF/IL-12) by peripheral blood mononuclear cells. J Exp Med. 1992; 176:1387-1398.

10. Manetti R, Parronchi P, Giudizi MG, et al. Natural killer cell stimulatory factor (interleukin 12 (IL-12)) induces T helper type 1 (Th1)-specific immune responses and inhibits the development of IL-4-producing Th cells. J Exp Med. 1993;177:1199-1204.

11. Trinchieri G. Interleukin-12 and its role in the generation of TH1 cells. Immunol Today. 1993;14:335-338.

12. Chan SH, Perussia B, Gupta JW, et al. Induction of interferon $\gamma$ production by natural killer cell stimulatory factor: characterization of the responder cells and synergy with other inducers. $J$ Exp Med. 1991;173:869-879.

13. Gately MK, Warrier RR, Honasoge S, et al. Administration of recombinant IL-12 to normal mice enhances cytolytic activity and induces production of IFN- $\gamma$ in vivo. Int Immunol. 1993;6:157-167.

14. Mehrotra PT, Wu D, Crim JA, et al. Effects of IL-12 on the generation of cytotoxic activity in human $\mathrm{CD}^{+} \mathrm{T}$ lymphocytes. J Immunol. 1993;151:2444-2452.

15. Robertson MJ, Soiffer RJ, Wolf SF, et al. Response of human natural killer (NK) cells to NK cell stimulatory factor (NKSF): cytolytic activity and proliferation of NK cells are differentially regulated by NKSF. J Exp Med. 1992;175:779-788.

16. Voest EE, Kenyon BM, O'Reilly MS, et al. Inhibition of angiogenesis in vivo by interleukin 12. J Natl Cancer Inst. 1995;87:581-586.

17. Brunda MJ, Luistro L, Warrier RR, et al. Antitumor and antimetastatic activity of interleukin 12 against murine tumors. J Exp Med. 1993;178:1223-1230.

18. Nastala CL, Edington HD, McKinney TG, et al. Recombinant IL-12 administration induces tumor regression in association with IFN- $\gamma$ production. J Immunol. 1994;153: 1697-1706.

19. Coughlin CM, Wysocka M, Kurzawa HL, et al. B7-1 and interleukin 12 synergistically induce effective antitumor immunity. Cancer Res. 1995;55:4980-4987.

20. Wiggington JM, Komschlies KL, Back TC, et al. Administration of interleukin 12 with pulse interleukin 2 and the rapid and complete eradication of murine renal carcinoma. J Natl Cancer Inst. 1996;88:38-43.

21. $\mathrm{Mu} \mathrm{J}$, Zou JP, Yamamoto $\mathrm{N}$, et al. Administration of recombinant interleukin 12 prevents outgrowth of tumor cells metastasizing spontaneously to lung and lymph nodes. Cancer Res. 1995;55:4404-4408.

22. Vagliani M, Rodolfo M, Cavallo F, et al. Interleukin 12 potentiates the curative effect of a vaccine based on interleukin 2-transduced tumor cells. Cancer Res. 1996;56: 467-470.

23. Noguchi Y, Jungbluth A, Richards EC, Old LJ. Effect of interleukin 12 on tumor induction by 3-methylcholanthrene. Proc Natl Acad Sci USA. 1996;93:11798-11801.

24. Rao JB, Chamberlain RS, Bronte V, et al. IL-12 is an effective adjuvant to recombinant vaccinia virus-based tumor vaccines. J Immunol. 1996;156:3357-3365.

25. Cavallo F, Signorelli P, Giovarelli M, et al. Antitumor efficacy of adenocarcinoma cells engineered to produce 
interleukin 12 (IL-12) or other cytokines compared with exogenous IL-12. J Natl Cancer Inst. 1997;89:1049-1058.

26. Fallarino F, Uyttenhove C, Boon T, Gajewski F. Endogenous IL-12 is necessary for rejection of P815 variants in vivo. J Immunol. 1996;156:1095-1100.

27. Colombo MP, Vagliani M, Spreafico F, et al. Amount of interleukin 12 available at the tumor site is critical for tumor regression. Cancer Res. 1996;56:2531-2534.

28. Desai BB, Quinn PM, Wolitzky AG, et al. The IL-12 receptor: distribution and regulation of receptor expression. J Immunol. 1992;148:3125-3132.

29. Hawley RG, Lieu FHL, Fong AZC, Hawley TS. Versatile retroviral vectors for potential use in gene therapy. Gene Ther. 1994;1:136-138.

30. Lieu FHL, Hawley TS, Fong AZC, Hawley RG. Transmissibility of murine stem cell virus-based retroviral vectors carrying both interleukin-12 cDNAs and a third gene: implications for immune gene therapy. Cancer Gene Ther. 1997;4:167-175.

31. Markowitz D, Goff S, Bank A. A safe packaging line for gene transfer: separating the viral genes on two different plasmids. J Virol. 1988;62:1120-1124.

32. Williams DA, Orkin SH, Mulligan RC. Retrovirus-mediated transfer of human adenosine deaminase gene sequences into cells in culture and into murine hematopoietic cells in vivo. Proc Natl Acad Sci USA. 1986;83:25662570.

33. Gately MK, Chizzonite R, Presky DH. Measurement of human and mouse interleukin-12. In: Coligan JE, Kruisbeek AM, Margulies DH, Shevach EM, Strober W, eds. Current Protocols in Immunology. New York: Wiley and Sons; 1995:Unit 6.16.1-6.16.4.

34. Plautz GE, Yang ZY, Wu BY, et al. Immunotherapy of malignancy by in vivo gene transfer in tumors. Proc Natl Acad Sci USA. 1993;90:4645-4649.

35. Tahara H, Zeh HJ, Storkus WJ, et al. Fibroblasts genetically engineered to secrete interleukin-12 can suppress tumor growth and induce anti-tumor immunity to a murine melanoma in vivo. Cancer Res. 1994;54:182-189.

36. Fakhrai H, Shawler DL, Gjerset R, et al. Cytokine gene therapy with interleukin-2-transduced fibroblasts: effects of IL-2 dose on anti-tumor immunity. Hum Gene Ther. 1995;6:591-601.

37. Zitvogel L, Tahara H, Robbins PD, et al. Cancer immunotherapy of established tumors with IL-12: effective delivery by genetically engineered fibroblasts. J Immunol. 1995;155:1393-1403.

38. Fearon ER, Pardoll DM, Itaya T, et al. Interleukin-2 production by tumor cells bypass $\mathrm{T}$ helper function in generation of an antitumor response. Cell. 1990;60: 397-403.

39. Gansbacher B, Zier K, Daniels B, et al. Interleukin-2 gene transfer into tumor cells abrogates tumorigenicity and induces protective immunity. J Exp Med. 1990;172:12171224.

40. Economou JS, Hoban M, Lee JD, et al. Production of tumor necrosis factor $\alpha$ and interferon $\gamma$ in interleukin-2treated melanoma patients: correlation with clinical toxicity. Cancer Immunol Immunother. 1991;34:49-52.

41. Leonard JP, Sherman ML, Fisher GL, et al. Effects of single-dose interleukin-12 exposure on interleukin-12 associated toxicity and interferon- $\gamma$ production. Blood. 1997; 90:2541-2548.

42. Bree AG, Schlerman FJ, Kavaini MD, et al. Multiple effects on peripheral hematology following administration of recombinant human interleukin 12 to nonhuman primates. Biochem Biophys Res Commun. 1994;204:11501157.

43. Atkins MB, Robertson MJ, Gordon M, et al. Phase I evaluation of intravenous recombinant human interleukin 12 in patients with advanced malignancies. Clin Cancer Res. 1997;3:409-417.

44. Gulber U, Chua AO, Schoenhaut DS, et al. Coexpression of two distinct genes is required to generate secreted bioactive cytotoxic lymphocyte maturation factor. Proc Natl Acad Sci USA. 1991;88:4143-4147.

45. Belsham J. Dual initiation sites of protein synthesis on foot-and-mouth disease virus RNA are selected following internal entry and scanning of ribosomes in vivo. EMBO J. 1992;11:1105-1110.

46. Jang SK, Wimmer E. Cap-independent translation of encephalomyocarditis virus RNA: structural elements of the internal ribosomal entry site and involvement of a cellular 57-kDa RNA-binding protein. Genes Dev. 1990;4: 1560-1572.

47. Zitvogel L, Tahara H, Cai Q, et al. Construction and characterization of retroviral vectors expressing biologically active human interleukin-12. Hum Gene Ther. 1994; 5:1493-506.

48. Martinotti A, Stoppacciaro A, Vagliani M, et al. CD4 T cells inhibit in vivo the CD8-mediated immune response against murine colon carcinoma cells transduced with interleukin-12 genes. Eur J Immunol. 1995;25:137-146.

49. Yang G, Mizuno MT, Hellström KE, Chen L. B7-negative versus B7-positive P815 tumor. J Immunol. 1997;158: $851-858$.

50. Schmitt M, Ikeda H, Nagata Y, et al. Involvement of T-cell subsets and natural killer (NK) cells in the growth suppression of murine fibrosarcoma cells transfected with interleukin-12 (IL-12) genes. Int J Cancer. 1997;72:505-511.

51. Tannenbaum CS, Wicker N, Armstrong D, et al. Cytokine and chemokine expression in tumors of mice receiving systemic therapy with IL-12. J Immunol. 1996;156:693-699. 